\title{
OPTIMUM SPOT WEED CONTROL TREATMENT FOR A NEW ZEALAND RADIATA PINE (PINUS RADIATA) PLANTATION
}

\author{
S.F. GOUS, B. RICHARDSON and M.O. KIMBERLEY \\ Forest Research, Private Bag 3020, Rotorua, New Zealand \\ Corresponding author: stefan.gous@forestresearch.co.nz
}

\begin{abstract}
A trial was established in the South Island of New Zealand to investigate the response of Pinus radiata to varying the area and duration of weed control around individual trees. Results after six years demonstrated that weed control was essential to ensure maximum survival and growth of Pinus radiata seedlings. Maintaining weed control for two seasons following planting resulted in marginally higher stand productivity than where weed control was applied in the year of planting only. A modelling approach was used to determine treatment effects in terms of a "time difference", and to make inferences on long-term treatment effects. Without weed control, tree volume six years after planting was more than 1.5 years behind trees given complete weed control. Spot vegetation control resulted in similar tree growth to total control, as long as the area and duration of weed control was greater than a $1 \mathrm{~m}$ spot maintained for 1 year.
\end{abstract}

Keywords: area, duration, weed, control, time difference.

\section{INTRODUCTION}

Spot weed control treatments may offer a number of management advantages to forestry landowners. These include the use of less chemical for plantation establishment and lower herbicide costs. In addition, spot weed control can be used where other vegetation management options are limited, such as with sensitive adjacent crops and where terrain is inaccessible for aerial application. Previous work on spot weed control in radiata pine for the first two years after planting showed crop growth gains from spot weed control. However, with only two years data available the optimal spot size and duration could not quantitatively be assessed (Richardson et al. 1996). Fifth year growth response of Douglas fir in Oregon, USA, suggested that to maximise growth, complete or near complete weed control was needed (Rose \& Ketchum 1998).

The objective of this trial was to determine the growth response of radiata pine to weed control treatments of varying area and duration. This information was required to identify environmentally sensitive weed control treatments that minimise costs and herbicide use while maintaining adequate crop survival and growth rates.

\section{METHODS}

The experiment was established in winter 1994 on a fertile, exposed, rolling, ex-pasture coastal site in Tokoiti Forest, South Otago. It was designed to test short-term (7-10 year) responses to a number of weed control treatments. The site had high soil fertility, an average annual rainfall of around $800 \mathrm{~mm}$ and a predominant vegetation cover of improved agricultural grasses.

The trial was planted with one-year-old, bare rooted GF26, radiata pine seedlings, at a spacing of $4 \mathrm{~m} \times 3 \mathrm{~m}$ (833 stems/ha). The experiment was established as a randomised complete block with five replicates and eight weed control treatments. Plots were $16 \mathrm{~m}$ $\mathrm{x} 15 \mathrm{~m}$ in size with the central 12 trees used for assessments. Weed control treatments were achieved with herbicides and were applied in the spring following planting. 
Treatments applied were no weed control; $1 \mathrm{~m}$ spot, $1.5 \mathrm{~m}$ spot and $2 \mathrm{~m}$ spot maintained weed-free for one year; $1 \mathrm{~m}$ spot, $1.5 \mathrm{~m}$ spot and $2 \mathrm{~m}$ spot maintained weed-free for two years; and complete weed control until canopy closure at five years. Tree height and diameter, growth, survival, degree of multi-leadering, and the size of weed-free areas around individual trees were measured annually for six years.

\section{Analysis}

Analysis of variance and least significant difference tests were used to test treatment effects on mean tree height, diameter, stem volume and stem volume per hectare (which includes the effect of mortality) at age six years.

Growth trends were analysed by firstly fitting sigmoidal growth curves to the diameter, height and volume (mean and per hectare) measurements for the complete weed control treatments in each replicate after subtracting size at planting. For diameter and volume, we used the Weibull function (Yang et al. 1978):

$$
y=a\left(1+e^{-(c t)^{b}}\right)
$$

For height, a better fit was achieved using the Chapman-Richards function (Richards 1959):

$$
y=a\left(1+e^{-c t}\right)^{b}
$$

An important aspect of these equations is that the parameter $c$ is a time scale multiplier. For example, if $a$ and $b$ are held constant but $c$ is halved, $y$ will take twice as long to reach a given value. For each annual growth increment, the value of $c$ corresponding to the measurements at the beginning and end of the increment, $y_{i-1}$ and $y_{i}$, was calculated by rearranging the growth equations. This was achieved for the Weibull function using:

$$
c=\left(-\ln \left\{1-\frac{y_{i}}{a}\right\}\right)^{1 / 6}-\left(-\ln \left\{1-\frac{y_{i-1}}{a}\right\}\right)^{1 / b}
$$

and for the Chapman-Richards function using:

$$
c=\ln \left(1-\left\{\frac{y_{i-1}}{a}\right\}^{1 / b}\right)-\ln \left(1-\left\{\frac{y_{i}}{a}\right\}^{1 / b}\right)
$$

Values of $c$ were obtained for each plot using the values of $a$ and $b$ obtained from the complete weed control plot in the same replicate of the trial. To quantify the competitive effects of weeds from any plot, the ratio of $c$ to the value of $c$ obtained from the total weed control plot in the same replicate was then calculated. This provided an estimate of the growth as a proportion of the complete weed control growth. By summing these, the cumulative growth years lost was calculated. Analysis of variance was then used to test the significance of the treatments on growth loss, and least significant differences were calculated. All analyses were performed using the SAS statistical analysis package.

\section{Survival}

\section{RESULTS AND DISCUSSION}

Tree survival was lowest $(60 \%)$ where there was no weed control and highest $(88 \%)$ with a $1 \mathrm{~m}$ diameter spot maintained for 2 years $(\mathrm{P}<0.05)$. However, there was no strong pattern of mortality with respect to area and duration of weed control. Survival was also poor $(77 \%)$ with complete weed control indicating that factors other than weed competition (e.g. wind exposure, browsing) were also influencing survival.

\section{Height, diameter, and volume of six-year-old trees}

Conclusions from examining treatment effects on growth were similar with respect to mean tree height, diameter, volume or total volume per hectare (including mortality effects). Mean tree growth, assessed using any parameter, was lowest in the no weed control treatment. Even the smallest amount of weed control (a $1 \mathrm{~m}$ diameter spot maintained for 1 year) produced large growth benefits. The highest value of any growth 
parameter was always found in the complete weed control treatment, but this was not significantly different $(\mathrm{P}>0.05)$ from the more intensive weed control treatments. The benefit from a second year of spot weed control was non significant in all cases except in the case of the $1 \mathrm{~m}$ spot treatment $(\mathrm{P}<0.05)$.

\section{Multi-leadering}

The incidence of multi-leadering increased as the area of weed control increased $(\mathrm{P}=0.05)$. This was probably related to rabbit or hare browsing in the first year. In addition, the lack of shade on the lower part of the tree in complete weed control plots encouraged vigorous growth of the lower branches. This effect may have been particularly important because the seedlings were planted deeply, sometimes resulting in steeply angled side branches.

\section{Growth trends over time}

Modelling of growth trends allowed calculation of the time difference (in years) between trees given a particular treatment and trees given complete weed control. In other words, this represents the years of growth lost by trees in a given treatment compared to trees in the best possible treatment (complete weed control).

One advantage of this approach is that it takes account of the natural growth trajectories of trees. For example, because the volume growth rate in the complete weed control plots increases over the first few years, the growth rates in the complete weed control plots will continue to be greater than in the weed competition plots even after competition ceases. This is simply because the complete weed control trees have progressed further along their natural, increasing growth trajectory for any given age. A simple comparison between volume increments will therefore always suggest that the competition effects continue longer than they actually do.

By the age of 6 years, the untreated control was lagging 1.8 years behind the complete weed control treatment in diameter $(\mathrm{P}<0.05)$. The next least-effective treatment $(1 \mathrm{~m}$ diameter spot maintained for 1 year) was 0.9 years behind the complete weed control treatment $(\mathrm{P}<0.05)$, while the best treatment $(2 \mathrm{~m}$ diameter maintained for 2 years $)$ was only 0.2 years behind $(\mathrm{P}<0.05)$. Effects on tree height had a more complex pattern, with some evidence of low levels of weed presence providing a slight growth stimulation compared with the complete weed control treatment in the first two years. Overall, effects were similar to but of smaller magnitude than diameter.

All treatment effects on growth (including mortality) appear to have reached a plateau by the age of 6 (Fig. 1). This strongly suggests that no further growth losses will occur for any treatment. In other words, there would be no growth gain from maintaining weed control beyond this point in time as growth curves are following parallel trajectories. Economic analysis, where stand growth is projected to the end of the rotation, would be required to determine the most cost-effective treatment. However, it is though that either a $1.5 \mathrm{~m}$ spot maintained for 1 year or a $1 \mathrm{~m}$ spot maintained for 2 years would be the most cost-effective treatments.

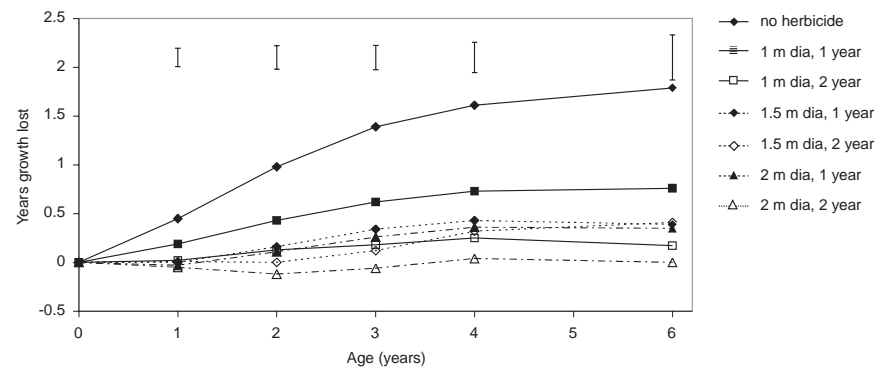

FIGURE 1: Years of stem volume per hectare growth lost in each treatment compared to the complete weed control treatment. 
The annual percentage loss in diameter growth for all treatments compared with the complete weed control treatment converged at age 3-4 (Fig. 2). This is an expected outcome, given that all treatments (except the untreated and complete weed control treatments) ceased to be maintained after age 2 . It is even possible that the significantly lower diameter growth for the control treatment during the final increment $(10 \%$ less growth than the control; $\mathrm{P}<0.05$; Fig. 2) can be attributed to the competition effect of neighbouring trees, given the small plot size. If this is so, competition effects actually ceased for all treatments at age 4 .

From this study it is clear that a spot of $1.0 \mathrm{~m}$ diameter if maintained weed free for two years produced significant growth gains over no weed control. However, larger spot sizes (1.5 $\mathrm{m}$ and $2 \mathrm{~m}$ spots) only had to be weed free for one year to produce even greater growth gains. Maintaining the spot weed free for a second year produced very little growth gains in the larger spots. Previous studies in Kinleith Forest indicated that there were significant growth gains from a second year's weeding (Richardson et al. 1997). Spot weed control in Douglas fir plantations in Oregon, USA, indicated that much larger spots $(6.0 \mathrm{~m})$ were required to maximise crop growth (Rose \& Ketchum 1998).

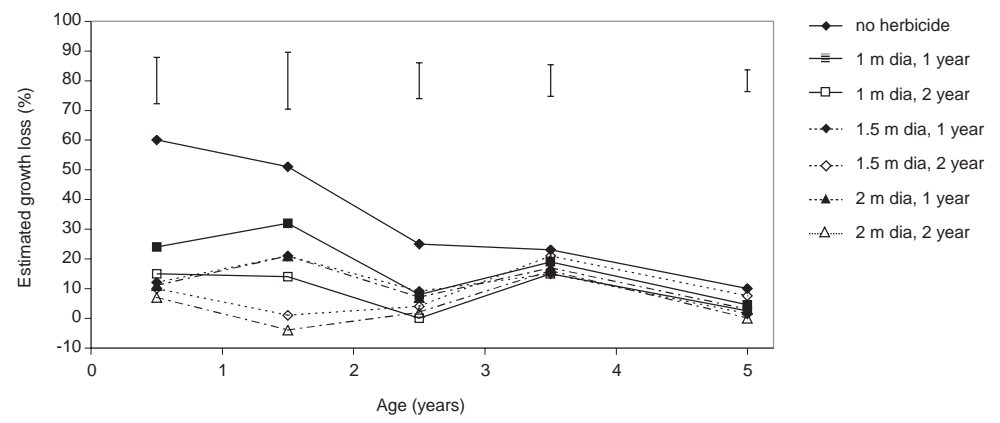

\section{FIGURE 2: Percentage diameter growth lost in each year for each treatment compared to the complete weed control treatment.}

\section{CONCLUSIONS}

In this study measurements of tree growth after six years on a fertile pasture site in South Otago showed that weed control was essential to ensure maximum survival and growth of radiata pine seedlings. Where a spot size of $1.5 \mathrm{~m}$ diameter or greater was applied, there was no significant benefit from a second year of control. Spot vegetation control resulted in similar tree growth to total control (time difference about 0.5 years or less), as long as the area and duration of weed control was greater than a $1 \mathrm{~m}$ spot maintained for 1 year.

Without weed control, tree volume growth was approximately 1.7 years behind trees given complete weed control. Total weed control, significantly increased multi leadering compared with less intensive weed control treatments.

The effects of weed control on tree growth had stabilised by age 6 years. In other words, trees from the vegetation control treatments were growing at a similar rate to completely weeded trees of the same size. Economic analyses would be required to identify the most cost-effective treatments, but at this stage it appears that either a $1.5 \mathrm{~m}$ spot maintained for 1 year or a $1 \mathrm{~m}$ spot maintained for 2 years would be the recommended options. 


\section{ACKNOWLEDGMENTS}

Funding for this work was provided by NZ Site Management Cooperative and the Foundation for Research, Science and Technology, Contract No. CO4X0006. City Forests provided land for the trial and additional support for fieldwork.

\section{REFERENCES}

Richards, F.J. 1959: A flexible growth function for empirical use. J. Exp. Bot. 10: 290300.

Richardson, B.; Davenhill, N.; Coker, G.;Ray, J.; Vanner, A.; Kimberley, M. 1996: Optimising spot weed control: First approximation of the most cost-effective spot size. N.Z. J. For. Sci. 26(1/2): 265-275.

Richardson, B.; Kimberley, M.; Pattison, A. 1997: Pinus radiata growth benefits from spot weed control in Kinleith forests. Proc. 50 th N.Z. Plant Prot. Conf.: 369-372.

Rose, R.; Ketchum, J.S. 1998: Fifth year growth response of Douglas-Fir to two years of spot weed control and controlling herbaceous versus woody weeds. Third International Conference on Forest Vegetation Management, Ontario, Canada. Forest Research Information Paper No. 141. Pp. 290-292.

Yang, R.C.; Kozak, A.; Smith, J.H.G. 1978: The potential of Weibull-type functions as flexible growth curves. Can. J. For. Res. 8: 424-431. 